\title{
Natureza, ética e pensamento comunicacional
}

Nature, ethics and communication Naturaleza, ética y pensamiento comunicacional Dayana K. Melo da Silva Universidade de São Paulo $<$ dayanamelo@usp.br>

\section{Resumo}

Do surgimento do pensamento racional na Grécia pré-socrática ao racionalismo moderno, a ideia de phusis foi se constituindo, inicialmente, como algo a ser compreendido, em seguida, como algo a ser explorado. A iminência de um colapso ambiental global provocado pela visão racionalista e objetificada da natureza nos conduz, entretanto, a questionar não apenas os limites da separação epistemológica entre natureza e cultura, mas também o próprio entendimento de natureza. Diante desse cenário, uma ética da comunicação, sendo esta última pensada neste estudo enquanto um campo de práticas e saberes, se aproximaria de uma cosmocomunicação, tal qual as concepções de cosmopolítica e cosmotécnica.

Palavras-chave: Natureza. Ética. Colapso Ambiental. Comunicação. Cosmocomunicação.

\section{Abstract}

From the emergence of rational thought in pre-Socratic Greece to modern rationalism, the idea of phusis was constituted, initially, as something to be understood, then as something to be explored. However, the imminence of a global environmental collapse caused by the rationalist and objectified view of nature, leads us to question not only the limits of the epistemological separation between nature and culture, but also the very understanding of nature. In view of this scenario, a Communication ethic, the latter being thought of in this study as a field of practices and knowledge, would approach cosmocommunication, just like the concepts of cosmopolitics and cosmotechnics.

Keywords: Nature. Ethics. Environmental collapse. Communication. Cosmocommunication.

\section{Resumen}

Desde el surgimiento del pensamiento racional en la Grecia presocrática hasta el racionalismo moderno, la idea de phusis se constituyó, inicialmente, como algo para ser entendido, luego como algo para ser explorado. Sin embargo, la inminencia de un colapso ambiental global provocado por la visión racionalista y objetivada de la naturaleza, nos lleva a cuestionar no solo los límites de la separación epistemológica entre naturaleza y cultura, sino también la comprensión misma de la naturaleza. Ante este escenario, una ética de la Comunicación, considerada esta última en este estudio como un campo de prácticas y conocimientos, se acercaría a una cosmocomunicación, al igual que las concepciones de cosmopolítica y cosmotécnica.

Palabras clave: Naturaleza. Ética. Colapso ambiental. Comunicación. Cosmocomunicación.

\section{Introdução}

Quando pensamos em natureza, uma das primeiras imagens que se desvela em nossa mente é a de um mundo e universo físico compostos por uma multiplicidade de seres e elementos, como animais, florestas, mares, rios, montanhas, céu e todas aquelas paisagens sublimes - pró- ximas e distantes - que aprendemos com os modernos a contemplar e usufruir. Essa realidade natural, finita na imensidão desse todo que nos rodeia, aparece-nos, no entanto, como uma realidade separada da realidade social. Nessa imagem de natureza, a Terra não é mais nosso abrigo, nossa casa, mas um simples reservatório de 
energia que ora exploramos, ora pensamos proteger de nós mesmos.

Em seu sentido filosófico primeiro, isto é, na ideia de phusis (фúoıs) concebida pelos pré-socráticos, a natureza designava o universo em sua totalidade, regido de acordo com uma ordem precisa, conforme indica a própria definição da palavra cosmos (kosmos / $\varkappa o ́ \sigma \mu$ os). A natureza (natura na tradução latina da palavra phusis) era pensada entre os gregos antigos como tudo o que está em presença ou que virá à presença, o processo e o movimento de nascimento, crescimento e morte dos seres. Mesmo quando se desenhavam os primeiros traços de um pensamento racional, o homem ainda estava integrado ao cosmos, ele ainda fazia parte da natureza e de seu fluxo de ocultamentos e desvelamentos. Contudo essa ideia de phusis sofreu uma mutação ainda entre os gregos, notadamente no pensamento de Platão, que vai influenciar, por sua vez, toda uma concepção moderna de natureza.

Assim, entre os séculos XVI, XVII e XVIII, com as transformações na física e no pensamento filosófico que resultaram na chamada revolução científica, as percepções de mundo, universo e natureza foram substancialmente redefinidas, bem como o lugar do homem em relação aos outros seres e elementos. $\mathrm{O}$ mundo não está mais dividido entre o celestial e o terrestre, mas unificado. Esse pensamento que se inicia com o Renascimento e seu humanismo característico, fundado no conhecimento experimental e na razão científica, entende a natureza como um conjunto de mecanismos físicos regidos por leis específicas, em suma, um objeto a ser dominado e explorado.
Um processo de objetificação e instrumentalização que está prestes a alcançar um nível no qual as condições de vida humana na Terra ficarão insustentáveis (CRUTZEN; STOERMER, 2000). Diante disso, é preciso entender as bases sobre as quais tanto a ideia de natureza como a separação entre natureza e cultura foram forjadas a fim de buscar construir novas visões de mundo capazes senão de interromper ao menos de amenizar o colapso que se anuncia. Nessa construção de novos mundos, ou criação de respostas, noções como cosmopolítica (STENGERS, 2007) e cosmotécnica (HUI, 2017) aparecem com muita potência, nos desafiando, inclusive, a conceber dentro dos nossos campos de observação outras noções igualmente potentes, como é o caso da noção de cosmocomunicação que pretendemos apresentar neste estudo.

\section{A invenção da ideia de natureza}

$\mathrm{O}$ pensamento racional sobre a natureza, assim como a própria ideia e imagem de natureza, seguiu um percurso reflexivo cujas origens se encontram na Grécia pré-socrática, mais especificamente no declínio do pensamento mitopoiético em detrimento de um pensamento racional. Isso significou o início de uma forma de compreender o cosmos ( óo $\mu \mathrm{o}$ ) na sua totalidade e com base em um discurso fundamentado no logos ( $\lambda$ óyos). Para Jean-Pierre Vernant (2013), o aparecimento do pensamento racional na Grécia no início do século VI a.C. substituiu as antigas cosmogonias, os relatos mágicos da origem do mundo e do universo, por novas cosmologias. O caos original é doravante convertido em uma ordem simétrica. 
Foram os antigos gregos, notadamente os milesianos, ${ }^{1}$ que conceberam a ideia de

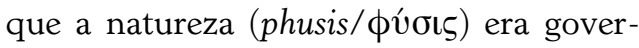
nada por leis e mecanismos próprios. Eles queriam entender a ordem do universo observando o mundo material; uma observação baseada na busca pelo princípio ou

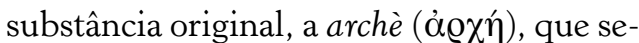
ria o princípio vital do universo. Com isso, os milesianos, em particular Tales, Anaximandro e Anaxímenes, construíram as bases para o desenvolvimento de um pensamento interessado na compreensão racional dos fenômenos naturais e não nos carateres míticos ou poéticos sobre os quais os relatos anteriores haviam sido construídos.

Desde a origem do mundo, de sua composição, de sua ordem, dos fenômenos meteorológicos, eles oferecem explicações livres de todo o imaginário dramático das antigas teogonias e cosmogonias: as grandes figuras dos poderes primordiais desapareceram; não há mais agentes sobrenaturais, cujas aventuras, lutas, façanhas formaram a teia de mitos da gênese, narrando o surgimento do mundo e a instituição da ordem; nem mesmo a alusão aos deuses que a religião oficial associava, nas crenças e nos cultos, às forças da natureza. (VERNANT, 2013, p. 112113, tradução nossa).

Para esses pensadores, a observação parte da análise de determinadas substâncias em direção a uma compreensão da vida e do universo como um todo. Para Tales, esse princípio original era a água em seu estado líquido; para Anaximandro, o apeiron (o ilimitado ou o indiferenciado); e para Anaxímenes, o ar. Assim, do engendramento dos deuses e das forças relacionais que caracterizavam os mitos de origem para os gregos, as análises pré-socráticas passaram a se apoiar nos processos de produção do mundo material pela observação racional e discutível de princípios ainda abstratos.

Com base nesse novo pensamento, os homens, os deuses e o universo passaram a ser compreendidos de forma unificada e homogênea, na qual tudo é natureza, constituindo partes do mesmo todo, da mesma phusis. Vernant afirma que: "Os caminhos pelos quais essa phusis nasceu, se diversificou e se organizou, são perfeitamente acessíveis à inteligência humana", acrescentando que, "Visto que há apenas uma phusis, que exclui a própria noção de sobrenatural, há apenas uma temporalidade. $\mathrm{O}$ original, o primordial, são despidos de sua majestade e mistério; eles têm a banalidade tranquilizadora dos fenômenos familiares" (VERNANT, 2013, p. 113, tradução nossa).

Todavia, embora essa concepção dessacralizada do universo tenha contribuído para o surgimento do pensamento racional, ela não se encerra aí. E mesmo que a ruptura entre o pensamento mítico e o pensamento racional tenha começado com os milesianos, ainda é possível observar na noção de phusis por eles articulada aspectos do pensamento mítico. As novas cosmologias preservaram vínculos com as antigas cosmogonias, de modo que havia uma estreita ligação entre os elementos da phusis que

1 A Escola de Mileto foi fundada na antiga cidade de Mileto, Jônia, no início do século VI a.C. Ela tem entre seus mais famosos pensadores Tales, Anaximandro e Anaxímenes, considerados por Aristóteles como os primeiros "físicos". Mileto também é considerada o berço da filosofia pré-socrática. 
compunham essa nova concepção de mundo e o imaginário ainda presente das antigas divindades do pensamento mitológico. Isso significa que: "Ao tornaram-se natureza, os elementos despojaram o aspecto dos deuses individualizados; mas permaneceram potências ativas e animadas, ainda sentidas como divinas" (VERNANT, 2013, p. 115, tradução nossa).

De fato, conforme a hipótese defendida por Francis M. Cornford (1970), houve uma continuidade do pensamento mítico no pensamento filosófico e científico dos milesianos, e não uma ruptura total. Em sua análise acerca da ideia de uma filosofia científica entre os jônicos, o filólogo britânico discute esses vínculos ocultos entre o muthos e o logos. Na verdade, para Cornford, os relatos pré-socráticos não apenas mantiveram a mesma estrutura narrativa dos relatos mitológicos, como também conservavam ligações intrínsecas entre as noções de phusis e logos, que até então não eram opostas.

Ao remontar a essas concepções pré-socráticas, Catherine e Raphaël Larrère as definem como cosmogonias e não como cosmologias, também designadas pela expressão histoire peri phusis (investigação sobre a natureza) (LARRÈRE; LARRÈRE, 2009, p. 26). Os autores lembram que, conforme demonstrado por Gérard Naddaf, em seu estudo sobre a origem e evolução do conceito grego de phusis, a estrutura linear, por ele classificada como "evolucionista", já estava presente na Teogonia de Hesíodo, que, como sabemos, começa com a narrativa da origem do universo (cosmogonia) e termina com a narrativa da origem da sociedade (politogonia), passando pela narrativa da origem do homem (antropogonia).
Naddaf (1992) reconstrói a origem do conceito de phusis com base na análise do Livro X de As Leis, no qual Platão se opõe à concepção de universo dos pré-socráticos, entendido como totalidade, e apresenta sua própria concepção acerca da origem e do desenvolvimento do mundo, na qual a ideia de um princípio ou substância originária é substituída pela ideia de alma, que é o próprio princípio do movimento. $\mathrm{O}$ pesquisador mostra que antes de chegar a uma problemática filosófica em Platão, o termo phusis designava em seu sentido primeiro o "crescimento", que incluía as ações de "origem", de "processo" e de "resultado".

Desse modo, a phusis, entendida como crescimento, designa para os milesianos todo o processo, da origem até a consolidação de uma coisa específica ou do universo entendido como totalidade. A phusis é, portanto, a substância primordial da qual tudo foi gerado. Desde o seu início, o pensamento filosófico foi associado a reflexões e discussões sobre o que os antigos chamavam de phusis, ou seja, a natureza, um princípio imanente baseado no vivido e na reatualização.

O termo grego phusis se refere ao que nasce e se desenvolve (de phuomai, "crescer"). É usado na Odisseia para designar as virtudes de uma planta que deve proteger Ulisses dos feitiços de Circe. Seu uso filosófico, pelos Milesianos, amplia seu significado: phusis designa então todo o processo que, do início ao fim, explica a constituição de uma coisa particular, ou da natureza em sua totalidade, do mundo. Ela inclui o princípio, ou substância primordial, da qual todas as coisas surgiram, o processo (crescimento ou diferenciação) que 
faz com que elas surjam, e o resultado desse processo, o conjunto disso que é produzido e suas propriedades características. (LARRÈRE; LARRÈRE, 2009, p. 27, tradução nossa).

Ademais, para além dos pensadores da Escola de Mileto, pensadores como Parmênides, Heráclito, Leucipo e Demócrito, entre outros, procuraram, cada um a sua maneira, refletir e articular um pensamento sobre o mundo físico e o cosmos. Desse modo, na filosofia de Platão, aparece a imagem do demiurgo, aquele que dá forma ao mundo, que modela a matéria, que transforma o mundo em artefato. Esse relato da gênese é completamente abandonado por Aristóteles, que substitui a busca pela origem por uma teoria das causas. Em Aristóteles "A natureza permanece um processo" (LARRÈRE; LARRÈRE, 2009, p. 39).

\section{Natureza-artefato e natureza- processo}

Com a revolução científica moderna, operada por Copérnico, Galileu, Kepler e Newton, a ideia de um mundo fechado e de um universo finito cede lugar à concepção de universo infinito (KOYRÉ, 2011). Nessa mesma direção, pensadores como Descartes, Locke, Leibniz, Berkeley, Hume e Kant, entre outros filósofos modernos, buscaram compreender a amplitude das transformações induzidas pela física moderna. Todavia toda essa racionalidade científica moderna, antiaristotélica em seus fundamentos, é definida por Catherine e Raphaël Larrère (2009, p. 63, tradução nossa) como uma "retomada da ambição platônica de acessar a estrutura inteligível, essencialmente matemática, do real", e também como continuidade da hipótese atomista de Epicuro, duas correntes opostas na Antiguidade.

A própria concepção de natureza como artefato (natura naturata), presente na filosofia moderna, tem suas raízes no pensamento de Platão. Do mesmo modo, a concepção de natureza como um processo (natura naturans), com base na qual essa primeira concepção de natureza foi constituída, também tem origem no pensamento grego. A esse respeito, Catherine e Raphaël Larrère (2009, p. 15, tradução nossa) acrescentam o seguinte: "A natura naturata (a natureza artefato) só se sustenta na existência de uma natureza-processo, de uma natura naturans, cuja ideia também provém dos Gregos. Só pode haver artefatos porque existe um processo para mantê-los".

Com base nessa leitura, o homem, assim como as obras e artefatos humanos, faz parte da natureza e isso lhe dá sua condição de existência. Logo, a cultura também é uma forma da natureza, ela é a "natureza cultivada". Porém, a concepção de natureza na época moderna não pode ser reduzida a uma concepção de natura naturata, ou seja, a uma natureza-artefato, um objeto, mas devemos também levar em consideração sua concepção de natura naturans, essa que caracteriza os processos que engendraram pesquisas, descobertas científicas e a relação dos homens com a imagem de natureza que eles próprios criaram.

Em suma, deve-se considerar que a concepção de natureza forjada na modernidade foi elaborada com base em duas concepções, uma que a vê a natureza como artefato e outra que a vê como um processo, cujos fundamentos são os do pensamento clássico grego. Porém, entre os gregos, o ho- 
mem, mesmo em sua posição de observador racional da natureza, fazia parte dessa natureza, enquanto entre os modernos ele se torna, conforme preconizado na fórmula cartesiana, mestre e possuidor da natureza, colocando-se em uma posição de exterioridade em relação a essa natureza, que está sempre disponível à exploração.

Tais transformações também estiveram associadas à expansão geográfica por meio da invasão do chamado "Novo Mundo", da escravização e comércio de seres humanos vindos do continente africano, e de um modelo de sociedade baseado na destruição de outros modos de existência e formas de associações humanas. $\mathrm{O}$ pensamento que se inicia com o Renascimento foi ancorado na física, no conhecimento experimental, no conhecimento empírico e, sobretudo, no racionalismo, com base no qual a natureza será vista como um instrumento de exploração, ou seja, um conjunto de mecanismos físicos regidos por leis específicas e do qual é necessário retirar os recursos ou mesmo artificializar, domesticar, apartar.

Essa revolução no pensamento também se dá pelo nascimento de uma nova astronomia e uma nova metafísica que rompeu com as cosmologias grega e medieval, mas na qual a razão científica ainda se mistura com a teologia. De tal modo, a estrutura ontológica do mundo e do universo torna-se objeto de discussão científica e disputa por significado. Como nos mostra Koyré (2011), é precisamente por meio de um objeto, o telescópio, que o campo de visão do homem se expande e que se aceita a ideia de um universo infinito.

$\mathrm{O}$ pensamento moderno seguiu um caminho aberto pela revolução científica, suas reflexões filosóficas, descobertas e invenções físicas. Transformações paradig- máticas que mudaram, mais uma vez, a relação do homem com o mundo e o universo. Assim, o homem toma o lugar do Deus único, tornando-se, ele mesmo, o centro do universo. Como resultado, a partir do século XVIII, ao lado do pensamento experimental, empirista, racionalista e de uma filosofia do sujeito, ocorreu um processo de dessacralização da natureza ainda mais agressivo porque mecanizado.

Com efeito, no início desse processo, como podemos observar nas obras de pensadores como Spinoza, Leibniz ou Malebranche, existe um elo de reconciliação entre a imagem de Deus e a da natureza. Para esse primeiro, por exemplo, natureza e Deus se fundem e têm o mesmo poder e o mesmo direito absoluto sobre todas as coisas. Então, com a cientificidade, o racionalismo e o mecanicismo moderno, os dogmas cristãos serão cada vez mais relativizados e a natureza passará a ser vista como uma máquina, um objeto.

Em Descartes, quando o homem desenvolve, por meio do saber experimental, um conhecimento científico capaz de fazê-lo conhecer os elementos e corpos que constituem o mundo e o universo, sua força e ação, ele se torna então o senhor e o possuidor da natureza, mas não apenas pelo gozo da terra, mas sobretudo para garantir a boa conservação da saúde humana. Esse filósofo ainda vê a natureza como a criação de Deus, como descrito no Gênesis, mas também um instrumento. Portanto, "Como realização externa de uma racionalidade que está em Deus (transcendente para Descartes, imanente para Spinoza), a natureza é apenas uma sequência racional, uma dedução finalizada" (LARRÈRE; LARRÈRE, 2009, p. 70, tradução nossa). 
Nesse sentido, com o pensamento cartesiano, principalmente pela sua influência no Iluminismo, o mundo natural viveu um novo processo de desencantamento e dessacralização. Submetida às ciências modernas, à tecnologia, aos desdobramentos da potência humana na Terra, a natureza é vista como um objeto e este objeto como um mero instrumento. Desvinculado da imagem de Deus e da natureza, o homem continua sua busca pelo paraíso terrestre.

O que está em jogo, de fato, é que o humanismo estabeleceu como paradigma universal todo o sistema de valores e crenças do homem ocidental civilizado. Foi o humanismo que justificou as invasões de territórios já povoados e construiu uma narrativa de descobertas, colonizando outros povos e explorando o mundo destes. Primeiro em nome de Deus, depois no lugar de Deus e em o nome de progresso. O humanismo, por meio das ciências modernas e das tecnologias, retira da imagem da natureza todos as suas narrativas mágicas, seus mistérios e encantos, pois o homem branco e civilizado seria a razão e verdade absoluta.

A ciência moderna não se apoia nem sobre a experiência imediata, nem apenas sobre o argumento racional. Ela deve produzir o objeto que ela conhece e autenticar os procedimentos de verificação. Da racionalidade argumentativa, comum a todos os cidadãos, característica do "saber grego", passamos assim a um modo de validação do conhecimento que toma emprestado seu modelo não mais do debate democrático, mas da instauração judicial da prova: trata-se de apresentar, diante de testemunhas qualificadas, um objeto específico. (LARRÈRE; LARRÈRE, 2009, p. 62, tradução nossa).

Em Sobre o "Humanismo", Martin Heidegger especifica claramente o sentido profundo dessa centralidade do humano que caracteriza a modernidade. De acordo com o filósofo, o humanismo é a ideia de que o ser humano é radicalmente diferente dos outros. $\mathrm{O}$ homem teria um papel privilegiado na existência. Claro, trata-se de um pensamento metafísico: "Todo humanismo funda-se ou numa Metafísica ou ele mesmo se postula como fundamento de uma tal" (HEIDEGGER, 1973, p. 351). É por isso que o humanismo concebe o mundo de um ponto de vista fixo e indiscutível, baseado em oposições binárias, garantindo o domínio da natureza pelo ente. Consequentemente, a modernidade é a consagração dessa visão.

Em suma, a modernidade foi fundada sobre o grande pilar universalista cujas estruturas também se baseiam no racionalismo, no individualismo e no progressismo. Nessa concepção, o homem, animal racional e portador da promessa do progresso, vê a natureza como um objeto, um instrumento que deve ser dominado e explorado. O homem, externo à natureza observada, torna-se o sujeito, e a natureza, o objeto. A metafísica moderna é a da salvação na Terra, de um progresso que levará o homem, partindo do racionalismo científico e técnico, a dominar os outros seres e o seu meio. Aqui, observamos a junção dos questionamentos heideggerianos sobre a técnica e o habitar, subvertidos na época moderna. 


\section{Por uma cosmocomunicação}

A promessa de salvação acabou, os eventos estão além de nós. Resta-nos entrar em acordo com esta Terra devastada, abandonando a imagem de uma natureza apartada do social, que ora devemos explorar, ora devemos preservar. No lugar de uma ecologia, uma ecosofia é forjada. E é precisamente no seio dessa ecosofia, da sabedoria da casa comum, que a imagem de Gaia retorna com toda sua complexidade e potência, seja na forma de revanche, como descreve por James Lovelock (2007), seja como uma intrusão, como indica Isabelle Stengers (2013).

Tal imagem nos convida a construir outras formas de pensar e habitar a Terra. O fracasso da modernidade foi acompanhado pela devastação do planeta, que evoca uma outra relação da humanidade com o ambiente e os outros seres, mais próxima daquilo que Michel Serres (2009) chamou de "contrato natural". Antiga divindade

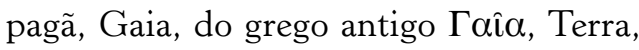
divindade ctônica, é a deusa primordial, a deusa-mãe, aquela que aparece, segundo a Teogonia de Hesíodo, após o caos. Para Lovelock, que desenvolveu sua hipótese antes mesmo do surgimento da hipótese do Antropoceno (CRUTZEN; STOERMER, 2000), Gaia é descrita como "uma entidade complexa que envolve a biosfera, atmosfera, oceanos e solo da Terra; a totalidade constituindo um feedback ou sistema cibernético que busca um ambiente físico e químico ideal para a vida neste planeta" (LOVELOCK, 2007, p. 10, tradução nossa).

Notemos, além disso, que Gaia pode reagir violentamente à pressão antropogênica a ponto de fazer com que a vida huma- na desapareça. Tristemente, essa revanche ou intrusão não ameaça apenas os responsáveis diretos pelas extrações e emissões, ou seja, os modernos, mas todos os modos de existência, incluindo os povos indígenas e outros povos tradicionais, animais, plantas etc. Isabelle Stengers e Bruno Latour, assim como outros importantes pensadores da contemporaneidade, retomam essa hipótese pensando Gaia como um agente político. Segundo Latour, diferentemente da imagem da natureza, Gaia "parece ser excessivamente sensível à nossa ação e parece reagir com extrema rapidez ao que sente e detecta. É por isso que devemos nos tornar prudentes, atentos, sim, sensíveis de volta" (LATOUR, 2014, p. 21, tradução nossa).

Em Latour, a imagem de Gaia surge como um conceito bem definido capaz de substituir a velha imagem da natureza, justamente para contestar a dicotomia moderna entre natureza e cultura e para definir o que se poderia constituir como uma nova geopolítica, pensada no sentido de uma política da Terra. Enquanto a natureza foi entendida na modernidade como um objeto separado do social, inalterado e cujos recursos eram ilimitados, Gaia, esse ser composto de seres vivos e não vivos, não pode ser entendida como um objeto, mas como uma força, ela própria viva, sensível, e que responde a todo tempo às nossas ações.

De acordo com Stengers, Gaia é a chave para entendermos as catástrofes que se aproximam: "Gaia é essa que faz intrusão numa história que os descendentes da revolução industrial contaram como a da emancipação humana libertando-se dos constrangimentos da 'natureza'" (STENGERS, 2014 , p. 148 , tradução nossa). Notemos também que essa intrusão não é punitiva 
porque é generalizada: "Gaia é esta figura da Terra com múltiplas representações que não pede amor nem proteção, apenas o tipo de atenção que convém a um ser poderoso e delicado" (STENGERS, 2014, p. 149, tradução nossa).

Para a filósofa, pensar na intrusão de Gaia significa pensar na nossa fragilidade diante das manifestações violentas que serão ocasionadas pelas transformações sofridas por esse "planeta vivo", daí a necessidade de construirmos respostas coletivamente. Stengers traz uma reflexão não apenas sobre a ecologia ou o meio ambiente, mas sobre a gravidade das questões climáticas.

Dar um nome, Gaia, a esse agenciamento de relações, é insistir sobre duas consequências dessas pesquisas. Aquilo de que dependemos, e que tantas vezes foi definido como "dado", a estrutura globalmente estável de nossas histórias e nossos cálculos, é o produto de uma história de coevolução, na qual os primeiros artesãos, e os verdadeiros autores em contínuo, foram as inúmeras populações de micro-organismos. E Gaia, "planeta vivo", deve ser reconhecida como um "ser" e não assimilada a uma soma de processos. (STENGERS, 2013, p. 51, tradução nossa).

Uma dessas respostas poderia ser encontrada na concepção de cosmopolítica (STENGERS, 2007), que, assim como a ideia de cosmotécnica (HUI, 2017), atua no sentido de indicar que "um outro mundo é possível". Desse mesmo modo, inserida em um contexto de profundas transformações no planeta, a Comunicação, entendida enquanto campo de práticas e saberes, isto é, um campo tecnológico e político por excelência, poderia ser igualmente articulada enquanto cosmocomunicação, tendo em vista o impacto dos fenômenos comunicacionais nos ambientes social e natural. Essa cosmocomunicação poderia mesmo substituir ou complexificar a ideia de uma ética da comunicação, dado que ela integraria além das construções discursivas a própria materialidade dos meios pelos quais esses discursos se dão, se propagam, se acrescem e/ou se refutam.

Afinal, para que esse outro mundo possível ganhe forma e que consigamos ao menos atenuar a iminente intrusão de Gaia, que metaforiza o iminente colapso ambiental global, é preciso que repensemos todas as ações que nos conduziram até esse momento. E um dos caminhos-chave para essa compreensão está no olhar em direção à separação entre razão e imaginário, cultura e natureza, sujeito e objeto, corpo e espírito, homem e técnica etc.; e na posterior tentativa de reconciliar alguns desses elementos e encontrar outras formas de interpretação do mundo e da técnica para além da concepção ocidental.

\section{Considerações finais}

Esses dois termos, Gaia e Antropoceno, indicam claramente a saturação do projeto ocidental moderno de conceber natureza e cultura como separadas e até opostas. Evidentemente, outras imagens, como a de Pachamama, deusa-terra da cosmogonia andina, também traz consigo uma potente metáfora para descrever a ambiência atual, sobretudo porque além da potência da terra, Pachamama carrega a potência do tempo. Nessas tradições antigas, as ideias de cultura e natureza não existiam pois não 
existia uma separação entre os chamados mundo social e mundo natural, tudo estava conectado dentro de uma mesma teia circular de tempo. E era no território, no sentido da Terra, que essas conexões se davam.

De fato, o entendimento de todos esses agenciamentos, rupturas e reconciliações nos traz problemas e questionamentos filosóficos, éticos, sociológicos, mas também comunicacionais. Sabe-se que o papel das tecnologias de comunicação, tal como o de outras tecnologias modernas, foi e continua sendo central nas alterações climáticas. Assim, do mesmo modo que a cosmopolítica (STENGERS, 2007) e a cosmotécnica (HUI, 2017) nos ajudam a pensar em termos de multiplicidade de mundos e visões de mundo, uma ideia de cosmocomunicação que considere outros paradigmas comunicacionais para além dos ocidentais, interligando narrativas e aparatos no processo de complexificação das práticas e saberes no campo da comunicação, nos parece igualmente fértil.
Partindo desse pequeno passo para trás, que nos ajudou a compreender as epistemologias sobre as quais o nosso ser e pensamento foram fundamentados, é preciso dar um passo adiante, na busca de uma formulação de cosmocomunicação que defina as práticas e os saberes comunicacionais para além do racionalismo e das dicotomias modernas. Se um "outro mundo é possível", para que esse novo mundo se construa será necessário articular outros conhecimentos, aqueles que foram deixados de lado pela modernidade e seus ideais de racionalismo, individualismo e progresso. Uma cosmocomunicação deve ser compreendida enquanto uma comunicação que pensa e faz pensar as multiplicidades, uma comunicação que sabe que, tal qual afirma Ailton Krenak (2020, p. 7), "Temos que abandonar o antropocentrismo". Com isso, abre-se um campo de complexidades, mas também de possibilidades, inclusive ontológicas. Articular todas essas perspectivas será tarefa de um estudo futuro.

\section{Referências bibliográficas}

CORNFORD, Francis Macdonald. Was the Ionian philosophy scientific? Studies in Presocratic Philosophy. London: Routledge and Kegan Paul, 1970.

CRUTZEN, Paul J.; STOERMER, Eugene. The 'Anthropocene'. Global Change Newsletter, n. 41, p. 17-18, 2000.

HEIDEGGER, Martin. Sobre o 'Humanismo’. São Paulo: Editora Abril, 1973. (Os Pensadores, XLV, p. 345-373).

HUI, Yuk. On Cosmotechnics: For a Renewed Relation between Technology and Nature in the Anthropocene. Techné: Research in Philosophy and Technology, v. 21, n. 2, p. 319-341, 2017.

KRENAK, Ailton. O amanhã não está à venda. São Paulo: Companhia das Letras, 2020.

KOYRÉ, Alexandre. Du monde clos à l'univers infini. Paris: Gallimard, 2011. 
LARRÈRE, Catherine; LARRÈRE, Raphaël. Du bon usage de la nature: pour une philosophie de l'environnement. Paris: Flammarion, 2009.

LATOUR, Bruno. L'Anthropocène et la destruction de l'image du Globe. De l'univers clos au monde infini. Paris: Éditions Dehors, 2014. p. 27-54.

LOVELOCK, James. The Revenge of Gaia: Why the Earth Is Fighting Back - and How We Can Still Save Humanity. London: Penguin, 2007.

NADDAF, Gerard. L'origine et l'évolution du concept grec de phusis. The Edwin Mellen Press: Lewiston, N.Y./Queenston, Ontario, 1992.

SERRES, Michel. Le contrat naturel. Paris: Flammarion, 2009.

STENGERS, Isabelle. La proposition cosmopolitique. In: LOLIVE, Jacques; SOUBEYRAN, Olivier (eds.). L'émergence des cosmopolitiques. Paris: La Découverte, 2007. p. 45-68.

STENGERS, Isabelle. Au temps des catastrophes résister à la barbarie qui vient. Paris: La Découverte, 2013.

STENGERS, Isabelle. Penser à partir du ravage écologique. In: HACHE, Émilie (ed.). De l'univers clos au monde infini. Bellevaux: Éd. Dehors, 2014. vol. 1.

VERNANT, Jean-Pierre. Les origines de la pensée grecque. Paris: Presses Universitaires de France, 2013.

Data do recebimento: 30/03/2021

Data do aceite: $01 / 05 / 2021$

Dados do autor:

Dayana K. Melo da Silva

http://lattes.cnpq.br/7405107228624107

Professora Contratada da Escola de Comunicações e Artes da USP e pesquisadora do Instituto de Estudos Avançados da USP. Doutora em Sociologia pela Université Sorbonne Paris Cité, mestre em Comunicação e Culturas Midiáticas pela UFPB, com estágio Procad de mobilidade acadêmica na ECO-UFRJ, graduada em Comunicação Social, com habilitação em jornalismo, pela UFPB, e em Ciências Sociais pela USP. Realizou pós-doutorado na ECA-USP. 
